\title{
Operational Changes and Performance Outcomes: Analysis on Hotels of Five Asia-Pacific Countries
}

\author{
Arghya Ray ${ }^{1}$ (D) $\cdot$ Lan $\mathrm{Ma}^{2}$
}

Received: 22 August 2021 / Accepted: 29 September 2021 / Published online: 20 October 2021

(c) Global Institute of Flexible Systems Management 2021

\begin{abstract}
COVID-19 pandemic has affected many businesses from all around the globe and one of them is the hospitality segment. Because of COVID-19 lockdowns and restrictions on travel, many hotels from all around the globe have suffered huge losses. After the COVID-19 restrictions were relaxed, hotels started opening the door for tourists with various precautionary measures. As the hospitality segment tries to recover from the setback due to COVID-19, this study explores the steps or strategies taken by hotels from five countries (China, Indonesia, India, Malaysia, and Thailand) in the Asia-Pacific region to attract tourists and improve their operations in the post-COVID era. For this study, the strategies undertaken and the customer reviews pertaining to 100 hotels from each of these five countries were considered. A mixed-method approach is used to analyze the effectiveness of the operations undertaken by the hotels. The study concludes with implications and future directions.
\end{abstract}

Keywords Challenges $\cdot$ COVID-19 $\cdot$ Hotels $\cdot$ Operational changes $\cdot$ Asia-Pacific $\cdot$ User generated content

\section{Introduction}

The recent pandemic due to Coronavirus Disease 2019 (better known as COVID-19), caused havoc all around the globe because of its highly contagious nature and its ability to cause "severe acute respiratory syndromes" (Lone \& Ahmad, 2020). With rising cases from all around the globe (around 113 countries) (Khanna et al., 2020), COVID-19 was declared as a pandemic by the World Health Organization (WHO) on 11th March 2020 (Cucinotta \& Vanelli, 2020). To maintain social distancing and curb the spread of the virus, governments from many countries had to impose lockdown for several days (Berman et al., 2020). Apart from the loss of human lives, the pandemic has also caused a change in the global economy (Jones et al., 2021). One of the most affected industries during the pandemic was the

Arghya Ray

mailarghyaray@gmail.com

Lan Ma

malan@sd.taylors.edu.my

1 FORE School of Management, Qutab Institutional Area, New Delhi 110016, India

2 Taylor's Business School, Taylor's University, 47500 Subang Jaya, Malaysia hospitality and tourism segment (Haydon \& Kumar, 2020). The most affected regions were the Asia-Pacific states (Clarke, 2020) because a good part of these countries revenues are generated from the tourism industry. With the COVID-19 restrictions in place and the fear of COVID-19 among people, the tourism industry suffered huge losses: around $\$ 83$ million in India (Gandhi, 2020), over $\$ 9$ billion in Indonesia (Straitstimes, 2020), around $\$ 2.7$ billion in Malaysia (TheStar, 2021), over $\$ 3.3$ billion in Thailand (Nikkei, 2021), and around $\$ 9.44$ billion in China (Hao et al., 2020). As the COVID-19 restrictions are relaxed, the hospitality sector is trying to recover from the losses they have suffered (Tyagi, 2020) with new strategies. For instance, giving special offers, lowering room rates, etc. (Ardani \& Harianto, 2021) and operational changes, like, regular monitoring of COVID-19 protocols in hotels, assigning duties effectively among available staff, etc. (Pandey et al., 2021; Shrivastava \& Shrivastava, 2021). Although hotels are trying to provide the best services to meet the changing customer needs (Crouch, 2021) using operational flexibilities, it is important to understand customer perspectives in the post-COVID era to understand how the hotels are performing.

The business problems that drive this research are as follows: First, there is a lack of comparative studies on the 
strategies hotels are following or the operational changes they are bringing in across different countries. A comparison will help hotels to pick up some good practices by other hotels and also help them improve their strategies. Second, there is a need to understand customers' perspectives to understand how the strategies followed by hotels are effective. Third, customer reviews provide ample opportunity to understand customer perspectives. Hence, in times like the COVID-19 pandemic, collecting data using traditional approaches can be challenging, utilizing online user-generated content can be useful. Thus, the research questions that drive this research are:

RQ1: What are the strategies or operational changes generally adopted by hotels in different countries to attract customers in post-COVID?

RQ2: What are the drivers of customer loyalty during post-COVID era?

RQ3: Do the drivers of customer loyalty differ for people belonging to two different emotion groups (high arousal and low arousal)?

The research objectives related to the research questions are as follows: (a) To understand the strategies generally used by hotels in different countries, and (b) To understand the effectiveness of the strategies adopted by understanding the drivers of customer loyalty during the post-COVID phase. In this study, a mixed-method approach is considered using only textual data collected from websites of 100 hotels from each of the 5 Asia-Pacific countries, China, Indonesia, India, Malaysia and Thailand. In the qualitative study, the strategies followed by hotels in these above-mentioned countries and the empirical analysis on the drivers of customer loyalty were explored. The study contributes to the existing literature by comparing the strategies hotels are following and the drivers of customers' loyalty in this post-COVID era by collecting data from websites of 100 hotels across five Asia-Pacific countries.

Section 2 following this introduction section, provides an overview of the relevant literature that builds up this work. Section 3 discusses the conceptual model and the hypotheses being examined in this study. Section 4 presents the research methodology. Sections 5, 6 and 7 contains the findings, discussions, implications, future scope and conclusions.

\section{Literature Review}

\section{Operational Changes and Performance Outcomes in the Post-COVID Era}

The pandemic COVID-19 has affected the hospitality sector badly because of less footfall, reduced revenue generation and fear among customers (Kumar, 2020). Not only because of the norms led down by the government and WHO, but also for making customers feel safe during their stay, hotels had to undergo operational changes and update their service standards (Chan, Gao, \& McGinley, 2021). Based on a study in China and Hong Kong (China), Chan et al. (2021) found that the changes in operations include thermal checking during check-in, check for proper use of surgical masks, noting travel history and symptoms (if any). Additional check involves use of a quick response code to track travel history of customers. The authors have also found that while international hotel chains try to benchmark their operations based on global standards, the medium and small-sized hotels are more flexible in their operations and enforce fewer specifications or checks. The authors have also found that hotels are using service innovation like, providing hygiene supplies, increasing sanitization protocols, and social innovations like, QR code scanning, alternative shifts of staff, etc. The authors have also found that hotels maintaining proper standards will generally not receive negative feedbacks. Kumar et al. (2021) based on their study of hotels in Kolkata India found that hotels will need strict regulations to enforce proper COVID-protocols. The authors also feel that housekeeping staff will be the most important resource in the post-COVID era because guests are concerned about the hotel hygiene and their safety. Kim et al. (2020) noted that because of this pandemic customers' will prefer hotels having robotstaff as compared to human-staff because of the significant effect of the moderator perceived threat. Romero and Lado (2021) based on their study in Spain also found that using robotic services improve customer attitude. Although innovations during COVID-19 may seem to attract customers, Sharma et al. (2021) feels that the effect depends on the innovation hotels use. While some innovations may prove effective other may not and hotels should discontinue such ineffective innovations. Based on the observation in Lebanese hotels, Yacoub and ElHajjar, (2021) feel that the initial preparedness was not there for such a pandemic, but now hotels have understood that they can't entirely depend on foreign customers, and hence are looking into operational changes like, better safety measures, focusing on schemes to attract local tourists, flexible bookings/cancellations, managing proper shifts, and more focus on information systems. Majumdar (2021)'s study on Indian hotels discovered several operational changes for the hotels to adopt to survive in the post-COVID. For instance, changing workforce structure, measures to attract local tourists, providing offers, reduction of prices, focusing on local supply chains, cost cutting by postponing maintenance, reducing labour costs, etc. Authors Jimenez-Barreto et al. (2021) feel that hotels also need to make changes in the way they communicate for attracting customers. Jimenez-Barreto et al. (2021) found that while exciting branded hotels benefit from 'numerical' quantifiers, sincere branded hotels benefit from 'numerical 
and verbal' quantifiers. Liu and Yang (2021) also found that the use of self-service technologies in hotels improved customer feedback. Although it is evident that researchers have found different strategies or operational changes adopted by hotels from different parts of the world, there is a clear gap in research trying to compare the strategies adopted by hotels from different countries.

Although hotels have adopted several strategies, the COVID-19 pandemic has caused unprecedented fear among travelers because of its contagious nature and ability to spread through contact. Thus, customers feared of safety and hygiene issues while staying in hotels (Bonfanti et al., 2021; Kiryakova-Dineva, \& Bozhkova, 2021). Additionally, if the customers fail to get proper help from the technology used by the hotels, they will face barriers that affect their behavioral intentions. Customer's views of staying in a hotel can also get affected by the views of the society in which they live in. Thus, although we note that operational or strategic changes have benefitted hotels in the post-COVID era, the fear and uncertainty of the virus can affect customer's willingness (Jian et al., 2020). Demir (2021) has also found that the measures considered by hotels during the pandemic affects customer perspectives. Additionally, the ways of providing services during the pandemic might affect the different dimensions of service quality, like, responsiveness, reliability, etc. (Ojha et al., 2021), which consequently affect customer loyalty (Hadid et al., 2021). It is thus important to explore the drivers of customer loyalty with respect to the hotel services. There is also a lack of comparative studies among countries to understand customer perspectives about hotel performances from different countries. This has also motivated us to compare data from 5 Asia-Pacific countries to explore the strategies followed by hotels and the perspectives of customers in this post-COVID era.

Scholars in recent years have explored how emotions affect brand attitude (Ray et al., 2021), review helpfulness (Chatterjee, 2020), etc. Capturing emotions, like, fear, anger, disgust, trust, surprise, etc. help to understand customers' feelings better (Cavanaugh et al., 2015). Ray et al., (2020a, 2020b) found an increase in algorithm performance while considering emotional aspects present in online reviews for predicting ratings. Thus emotions can also help in understanding customer behaviour. Emotions can be categorized based on the level of valence involved (negative and positive), arousal (high and low), etc. Allard et al. (2020) have found that both aged and young people portray high arousal emotions when they feel that it's the best way to solve a particular issue. Although, emotions and more specifically arousal emotions can help to understand customer behaviour and satisfaction better (Ray et al., 2021), there is a clear lack of studies on understanding how customers from different arousal emotional groups react to a particular situation. Users nowadays usually express their views through online reviews on hotel websites or other traveling sites. Exploring this will help to understand that how the strategies or operational changes undertaken by hotels affect users.

\section{User-generated Content (UGC) and Textual Analysis}

The last decade has witnessed a growth in the online content generated because of the penetration of the internet and the growing popularity of various social-media platforms (Ray \& Bala, 2020). UGC has several advantages: (a) the easy availability of large amount of data containing rich information related to customer perspectives can help organizations (Berger et al., 2010; Gensler et al., 2016); (b) the lack of commercial biasness in UGC (East et al., 2008); (c) UGC can help in analyzing changes in customer views over time (Gensler et al., 2016). These advantages have led to the rise in studies using UGC in recent years. Although UGC mainly refers to online customer reviews, in this study the information posted in hotel websites by hotel managers is also referred as UGC. UGC can be analyzed using various techniques, like, word-frequency analysis (Taft, 1979), thematic analysis (Ray \& Bala, 2021), sentiment and emotion analysis (Ray et al., 2020a, 2020b), natural language processing based structural equation modeling (NLP-SEM) (Ray \& Bala, 2021), etc. In this study, word frequency analysis, thematic analysis, sentiment and emotional analysis and NLP-SEM is used.

\section{Hypotheses Formulation and Conceptual Model}

To understand how the hotel's strategic/operational changes affect customer views in the post-COVID era in an empirical manner based on customers with high arousal emotions vs. customers with low arousal emotions, a multi-group analysis is used to examine the impact of hotel's facilities, credibility, empathy, responsiveness and reliability on affective loyalty. Here, affective loyalty refers to the customer's liking or affinity towards a hotel (Lee et al, 2014; Lin, 2010). The model is formulated based on the variables used by existing researchers (Fig. 1).

Hotel facilities mainly refer to the tangible facilities that hotels are providing nowadays to attract customers, like, complementary breakfasts, room services, extra services, etc. (Abrudan et al., 2020). In the post-COVID era, customers are looking for better facilities that will reduce their risk of staying in the hotels. Additionally, customers are also looking for extra facilities like, breakfast in rooms, special arrangements for celebrating in the rooms, etc. Hotels around the world are trying to bring changes in tangibles like, technology, arrangements, and appearance (Fatima, \& Razzaque, 2014) of hotels to attract customers 


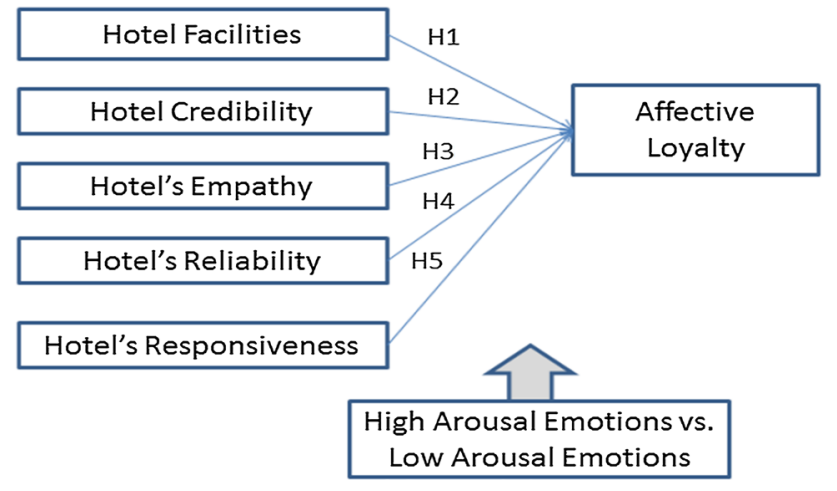

Fig. 1 Conceptual model to explore customer views

and demonstrate that they are maintaining proper safety and security (Krzysztof, \& Jadranka, 2020). Demir (2021) has also found hotel facilities affecting customer's perspectives. So from hotel's facilities this study explores if the hotel's physical cues and extra benefits affect customer views. Thus, we propose:

H1 The facilities provided by hotels have a significant impact on customer's affective loyalty.

Credibility refers to the organization's reputation and the quality of the information that the organization provides (Mahon, \& Wartick, 2003; Shah \& Ravana, 2014). In the post-COVID era, if the hotels are credible and people know that the hotels will not provide false information, customers will be inclined to use the hotels (Lanz, 2020). However, some hotels may advertise information about customer safety and extra facilities provided in hotels but the reality might be somewhat different. Although the message credibility will affect customer behaviour (Balaji et al., 2021), but it will affect customer loyalty negatively. Additionally, people will also be certain of the quality of services they expect to get at the hotels, if the hotels are credible. In this post-COVID era, people will tend to book hotels which have a reputation of providing good services to customers and managing customer safety properly. Post-COVID it is important to understand the safety protocols undertaken by hotels and hence if hotels are credible people will not have the fear of staying in hotels. Thus, we hypothesize:

$H 2$ Hotel's credibility has a significant positive impact on customer's affective loyalty.

Empathy refers to the ability to understand the mental state of others (Fatima, \& Razzaque, 2014; Parra, 2013). Empathy forms an important dimension of the service quality (SERVQUAL) model as well (Ojha et al., 2021). Hadid et al. (2021) have found that empathy affects customer loyalty in presence of mediator satisfaction. In an interesting study, Mishra and Sharma (2021) have found that expectations are affected by empathy. Hotels that are empathetic to customers (EHL, 2021) will tend to do well in the post-COVID era. With the uncertainty around, if hotels understand customer's perspectives and provide flexible check-in or check-out and full-refund in case of cancellations, the customers will also be satisfied and will be inclined towards using the hotel/hotel chain again. Thus, we feel:

$H 3$ Hotel's empathy has a significant positive impact on the customer's affective loyalty.

Reliability refers to the consistency and accuracy of the provided services as per the promises made (Fatima, \& Razzaque, 2014; Wang, \& Wang, 2021) and is another dimension of SERVQUAL model (Mishra \& Sharma, 2021; Ojha et al., 2021). Hence, reliability also determines the quality of the hotel. Qomariah, and Lestari (2019) have found that service reliability affects customer satisfaction. Customer fear staying in hotels because of factors like, safety and hygiene in hotels (Bonfanti et al., 2021; Kiryakova-Dineva, \& Bozhkova, 2021). If hotels assure customers about their safety within the hotel premises during their stay, and meet the expectations, customers will be satisfied and will develop affective loyalty towards the hotel. Thus, we hypothesize:

$H 4$ Hotel's reliability has a significant positive impact on the affective loyalty of customers.

Responsiveness refers to the service agility or swiftness of the provided services (Fatima, \& Razzaque, 2014) and is another dimension of SERVQUAL (Mishra \& Sharma, 2021; Ojha et al., 2021). Along with empathy and reliability, responsiveness also determines the service quality at a hotel. Although Kim et al. (2020) found that customers will prefer robotic-staff as compared to human-staff in the post-COVID era, Kumar et al. (2021) feel that human-staff will have an important role to play, like, making regular checks, keeping everything clean, etc. (Chan et al., 2021). However, with reduced staff and with alternative shifts being implemented in hotels (Chan et al., 2021), there might be a delay in providing services which can affect customer's views. Hotels that are able to provide prompt services to customers are doing well and will be able to retain customer relationship and build a loyal customer base. Thus we propose:

H5 Hotel's Responsiveness has a significant positive impact on affective loyalty of customers.

Arousal emotions refer to the set of emotions like, anger, fear, joy, etc. which escalate the mental state of a person (Lim, 2016). High arousal emotions (Cavanaugh et al., 2015; Ray et al., 2021) excite an individual more and is often considered less credible (Chatterjee, 2020) because customers depicting high arousal emotions tend to take decisions all of a sudden. Whereas, customers portraying low arousal emotions, like, sadness (Cavanaugh et al., 2015; Ray et al., 2021) does not get excited all of a sudden and hence these emotions are considered neutral and credible (Chatterjee, 2020; Rasa et al., 2020). This study attempts to explore if the drivers of affective loyalty differ for customers who have portrayed 
high arousal emotions with respect to customers who have portrayed low arousal emotions. Thus, we hypothesize:

H6 Customers portraying (a) high arousal emotions or (b) low arousal emotions will have different factors affecting their affective loyalty.

\section{Research Methodology}

In this study, a mixed-method approach: a qualitative study to understand strategies followed by hotels in the postCOVID era; and a quantitative study to examine customer perspectives to understand the performance of hotels in the post-COVID era (refer Figs. 2, 3). While a qualitative study helps to increase the possibility of capturing sensitive in-detail information from the participants (Creswell, 2009), a quantitative-based study helps empirically test the conceptual model (Ray et al., 2019). A mixed-method approach helps to extend and test the possibilities of the perceptions captured in qualitative study (Ray et al., 2019). For the qualitative study, strategies followed by 100 hotels (as mentioned in their websites) were collected each of the five countries selected for this study namely, China, India, Indonesia, Malaysia and Thailand in the post-COVID era. For the empirical analysis, customer reviews from these hotel websites were collected (1247 reviews). The selection and inclusion criteria are mentioned in Fig. 2. Before proceeding with the analysis, data cleansing was done where unwanted symbols and words were removed, and the words were changed to the root form. For the qualitative study, word-frequency analysis, word-cloud and topic modeling based thematic analysis was conducted to explore the main strategies that hotels adopt. Both word frequency and word cloud analysis were performed to get an overview of the major topics used in the textual data obtained (Fischer, \& Stoffel, 2014). While word frequency provides a textual output, word cloud provides a much more meaningful visualization (Padmanandam et al., 2021). Topic modeling helps to create a topic-terms matrix and provides probability scores based on the concept that a topic is composed of several terms and several topics presented in a particular document (Ray \& Bala, 2021). Topic modeling helps in performing a much deeper analysis of textual data through content analysis (Hagen, 2018), path analysis (Ray \& Bala, 2019; Ray et al., 2020a, 2020b), etc. For the quantitative analysis sentiment, emotional analysis, and NLP-SEM technique (Ray \& Bala, 2021) was utilized on the online reviews. Sentiment analysis helps to capture the polarity or valence (positive, negative or neutral) of the customer reviews. Meanwhile, the emotional analysis helps to provide a much deeper analysis by capturing the different emotions (anger, fear, disgust, sadness, anticipation, trust, surprise and joy) expressed in the textual data (Ray et al., 2021). In this study, the thematic analysis is done based on topic modeling by utilizing a common consensus among the authors on the topics which meet the research objectives (Ray \& Bala, 2021; Ray et al., 2019). For the NLP-SEM analysis, the probability scores were considered for the relevant topics from the topic-terms matrix of the online reviews and normalized to a Likert-scale form for performing the structural model analysis (Ray \& Bala, 2021). The analysis was done using R, Python and Smart PLS (3.3.2) (Ringle et al., 2015).
Fig. 2 Stepwise research flowchart

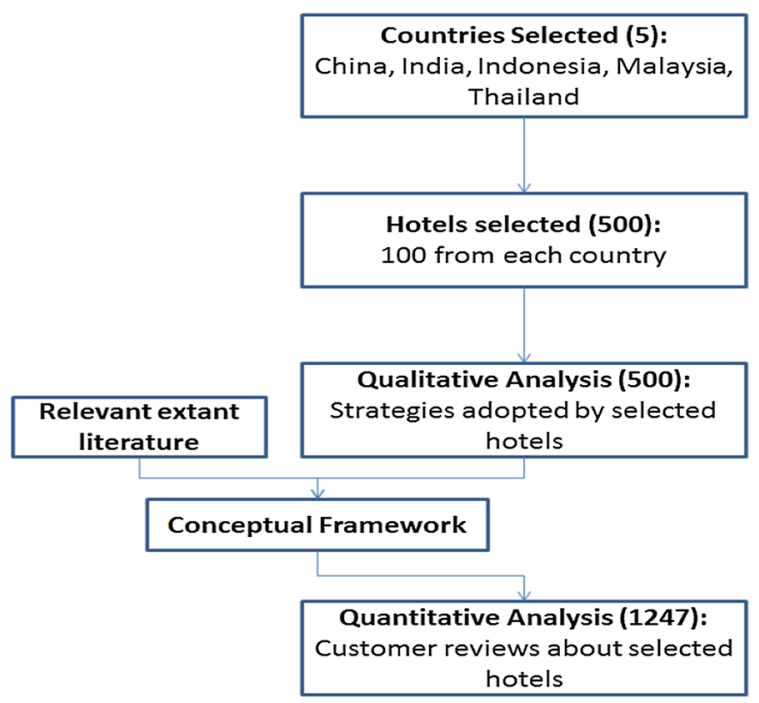

Selection Criterion: Countries in Asia having good tourist footfall
Selection Criterion: Above 2-star rated hotels.

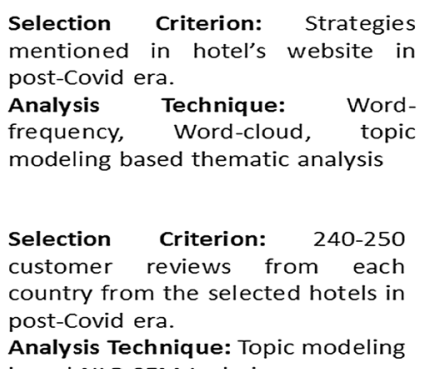

Selection Criterion: Strategies mentioned in hotel's website in post-Covid era.

Analysis Technique: Wordfrequency, Word-cloud, topic modeling based thematic analysis

Selection Criterion: 240-250 customer reviews from each country from the selected hotels in post-Covid era.

Analysis Technique: Topic modeling based NLP-SEM technique. 


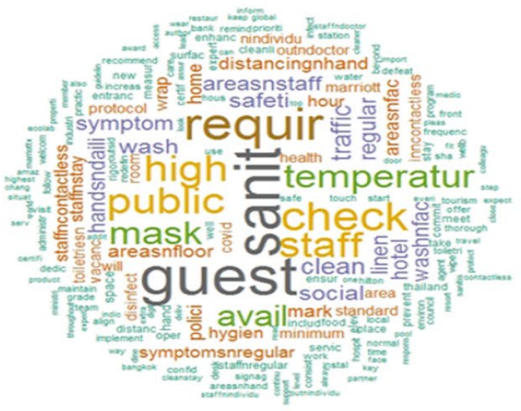

(a) Thailand

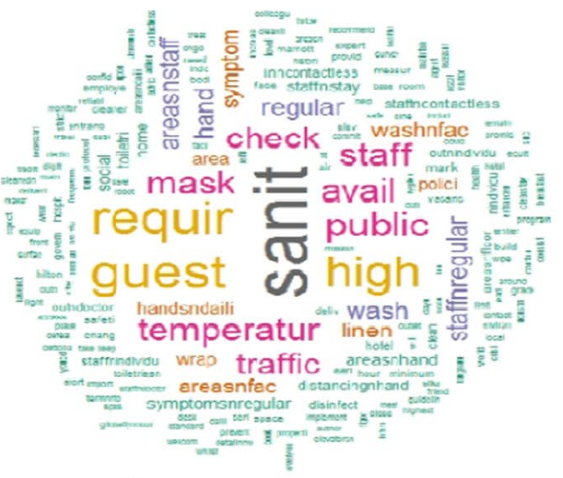

(d) China

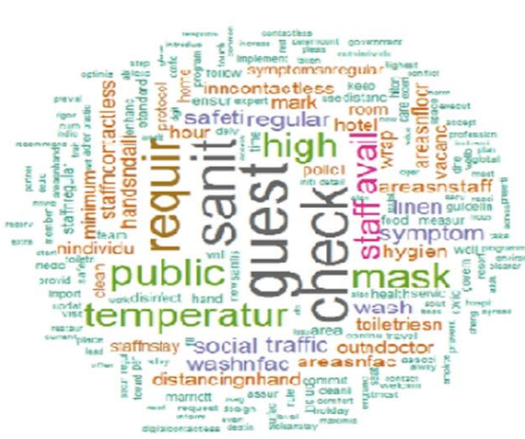

(b) India

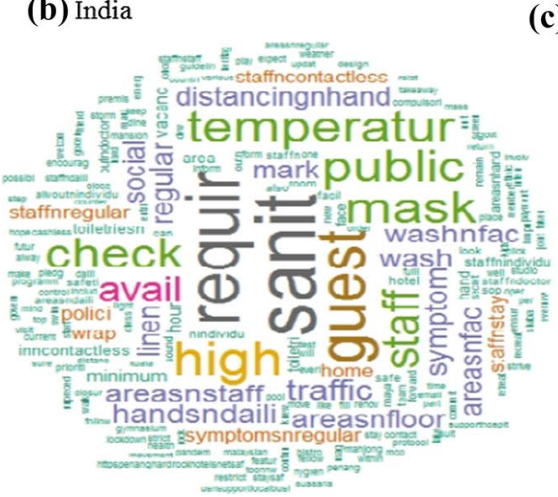

(e) Malaysia

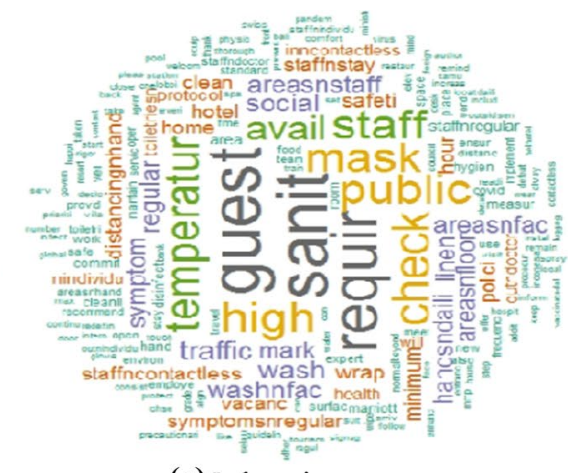

(c) Indonesia

Fig. 3 Word-cloud on the information available in websites of hotels in different countries

Table 1 The words based on frequency (descending order) used by hotels of different countries

\begin{tabular}{lllll}
\hline Malaysia & China & Indonesia & India & Thailand \\
\hline Sanitization & Sanitization & Sanitization & Guest & Sanitization \\
Require & Require & Guest & Check & Guest \\
Guest & Guest & Require & Sanitization & Require \\
High & High & Check & Require & Check \\
Mask & Public & Public & Public & High \\
Public & Avail & High & High & Public \\
Tempera- & Tempera- & Mask & Tempera- & Staff \\
ture & ture & & ture & \\
Check & Mask & Staff & Mask & Temperature \\
Staff & Staff & Tempera- & Staff & Mask \\
& & ture & & \\
Avail & Check & Avail & Avail & Avail \\
\hline
\end{tabular}

\section{Findings and Discussion}

Table 1 and Fig. 3 show the top 10 mostly used words in the information page of the hotels and the word-cloud of hotels across the consideration countries, respectively. This study found that the frequently used words are similar across different countries, which indicates that most hotels have prioritized and reset their services according to
COVID-19 protocols during their recovery stage. An interesting observation is that hotels in different countries tend to 'copy-paste' the COVID-19 messages to their customers on their websites without contextualizing the messages based on the COVID-19 situation in their host countries. Another observation from Table 1 is that except India, hotels from countries have used 'sanitization' the most. The authors have also noticed that the word 'mask' has not been ranked as top 5 words in any of hotel websites across the countries.

Table 2 summarizes some of the most frequently occurring themes based on topic-modeling results conducted on the available information from different hotels. The themes are derived based on mutual agreement between two researchers (Boyatzis, 1998). Apart from regular temperature checks and mask requirements in hotels from all countries, some other major themes from different countries are: Malaysia (hotel room safety), China (regular wash), Indonesia (mark symptoms), India (social distancing), and Thailand (guest room checks).

Figures 4, 5 display the results of the overall sentiment and emotional analysis of the reviews given by customers about hotels in the countries of the consideration. The study findings show that the overall sentiment and emotions portrayed by customers about hotels in different countries are mostly positive. The authors have also noted that the 
Table 2 Thematic analysis (based on topic modeling) conducted on hotels of different countries

\begin{tabular}{lllll}
\hline Malaysia & China & Indonesia & India & Thailand \\
\hline Hotel room safety & Required policies & Temperature check & Mask policies & Require temperature check \\
Regular wash & Disinfectants and sanitizers & Clean protocols & Safety checks & Guest room checks \\
Regular temperature check & Mask requirements & Masks must & Social distancing & Mask requirements \\
Mask requirement & Regular wash & Regular safety checks & Protocols & Sanitization requirements \\
Distancing & Check temperature & Mark symptoms & hygiene and sanitization & Protocols \\
\hline
\end{tabular}

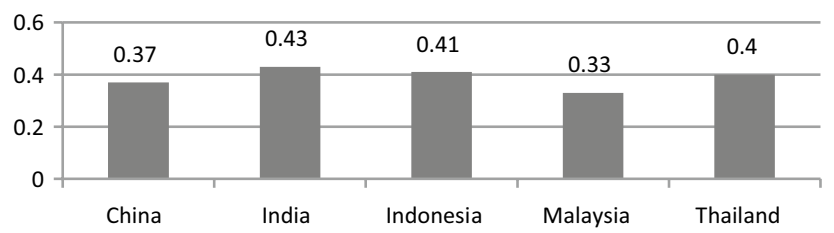

Fig. 4 Sentiment analysis of the data collected from hotels in different countries

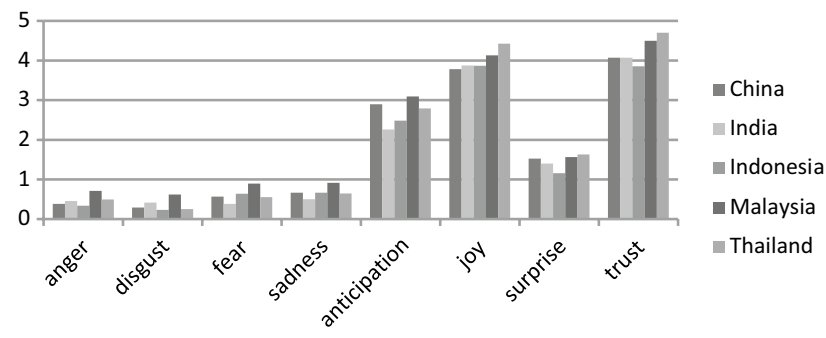

Fig. 5 Emotional analysis of the data collected from hotels in different countries

emotions like trust and joy are showing more significant effect than other emotions (refer Fig. 5). This indicates that people are satisfied with the strategies adopted by the hotels. One interesting observation is that hotel consumers in Malaysia have expressed more negative emotions like, anger, fear, disgust, and sadness than other countries under the similar pandemic situation, whereas in Thailand people hold more positive emotions like, joy, surprise and trust towards hotel services. The possible reason is that in the post-COVID era Thailand hotels are focusing more on cleanliness, customer safety and trying to increase the footfall of tourists because the Thailand economy is mostly dependent on the tourism industry (Manakitsomboon, 2021). Malaysian economy, on the other hand, is mostly dependent on agriculture, industry and services (O'Neill, 2021). Thus, the focus is not much on the tourism segment and tourists visiting Malaysian hotels during the post-COVID phase expressed a great concern over cleanliness, professional room services, safety from COVID-19 as evident from the customer reviews. Another reason is that Malaysia's frequent Movement Control Order (MCO), surging numbers of COVID cases, and insufficient effective policies to assist the hotel players further worsened the situation in hotel business (Foo et al., 2020). The concerns each hotel worker over job security, job safeness and workload issues may also result in unprofessional services. Thus, tourists who stay in Malaysian hotels in the post-COVID phase are more likely to develop negative feelings towards hotel workers compared to other countries.

The results of the NLP-SEM based analysis is shown in Tables 3, 4. The themes generated based on topic-modeling on the customer reviews are mapped on the different variables under consideration and the results of the SEM based analysis show good factor loadings $(>0.5)$ and variation inflation factor scores $(<3.0)$. The composite reliability scores are greater than 0.65 (Hair et al., 1998), and the discriminant validity criteria is also met (Fornell \& Larcker, 1981). The model showed satisfactory fit (Standardized Root Mean Square Residual (SRMR) score 0.095). The hypotheses H1, H2, H3, and H5 are significant (refer Table 4 and Fig. 6) which show that customers value hotel facilities, hotel credibility, empathy, and responsiveness. It is clear that customers who are having high arousal emotions are more inclined towards hotel facilities, while customers portraying low-arousal emotions are affected by hotel facilities, credibility, empathy, and responsiveness (refer Table 4). Based on the path-strength this study concludes that hotel facilities have a much higher impact on customer's loyalty than other variables.

The findings of the study show that hotel facilities play an important role affecting customer's loyalty in this postCOVID era. This aligns with what researchers (Fatima, \& Razzaque, 2014; Krzysztof, \& Jadranka, 2020) have found. This shows that facilities to enhance safety and security (Krzysztof, \& Jadranka, 2020), extra facilities like, complimentary breakfasts, room services, extra services, etc. (Demir, 2021). Because of fewer footfalls, hotels nowadays are providing various facilities to not only attract customers but also to ensure their safety from virus. Hotels that lack in these aspects are losing out in the competition. The authors also note other factors like empathy, responsiveness and credibility have a significant impact. This is also in line with what researchers (Chan et al., 2021; Hadid et al., 2021; Shah \& Ravana, 2014) have noted. This 
Table 3 Measurement Items, Factor Loadings, Variation Inflation Factor (VIF)

\begin{tabular}{llll}
\hline & Measurement items (Themes) & Factor loadings & VIF \\
\hline Hotel's facility (HF) & HF1:Free Breakfast & 0.734 & 1.188 \\
& HF2:Checks on each floor & 0.733 & 1.192 \\
Hotel credibility (HC) & HF3:Offers & 0.616 & 1.075 \\
& HC1:Clean room & 0.691 & 1.035 \\
& HC2:Delicious food & 0.725 & 1.052 \\
Hotel's empathy (EMP) & HC3:Nice staff & 0.548 & 1.059 \\
Hotel's Reliability (REL) & EMP1:Check-in and Check-out & 0.794 & 1.027 \\
& EMP2:Special care & 0.728 & 1.027 \\
Hotel's Responsiveness (RES) & REL1:Good Staff & 0.910 & 1.018 \\
& REL2:Trustworthy & 0.531 & 1.018 \\
& RES1:Timely & 0.513 & 1.035 \\
Loyalty (LOY) & RES2:Prompt & 0.504 & 1.015 \\
& RES3:Good service & 0.820 & 1.048 \\
& LOY1:Love/like service & 0.527 & 1.018 \\
& LOY2:Great Experience & 0.654 & 1.029 \\
& LOY3:Enjoy & 0.700 & 1.016 \\
\hline
\end{tabular}

Table 4 Hypotheses results

\begin{tabular}{|c|c|c|c|c|c|c|}
\hline \multirow[t]{2}{*}{ Hypotheses } & \multicolumn{2}{|c|}{ Combined analysis } & \multicolumn{2}{|c|}{ H6a.High arousal emotions } & \multicolumn{2}{|c|}{ H6b.Low arousal emotions } \\
\hline & $\beta$-value, $\mathrm{p}$-value & Supported? & $\beta$-value, $\mathrm{p}$-value & Supported? & $\beta$-value, $\mathrm{p}$-value & Supported? \\
\hline H1:HFLOY & $0.309,0.000$ & Yes & $0.406,0.000$ & Yes & $0.277,0.000$ & Yes \\
\hline H2:HCLOY & $0.090,0.005$ & Yes & $0.069,0.196$ & No & $0.091,0.022$ & Yes \\
\hline H3:EMPLOY & $0.091,0.019$ & Yes & $0.072,0.193$ & No & $0.095,0.073$ & Yes \\
\hline H4:RELLOY & $0.040,0.200$ & No & $0.016,0.716$ & No & $0.059,0.178$ & No \\
\hline H5:RESLOY & $0.092,0.003$ & Yes & $0.074,0.091$ & No & $0.092,0.023$ & Yes \\
\hline
\end{tabular}

LOY loyalty, HC hotel credibility, EMP Hotel's empathy, HF Hotel's facility, RES Hotel's responsiveness, REL Hotel's reliability

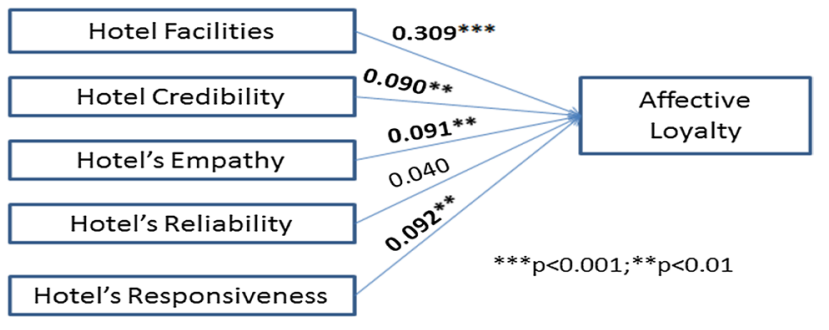

Fig. 6 Path Analysis combined results

is because nowadays due to uncertainty, trips are often getting cancelled. If the hotels understand the plight of customers and provide full refunds, the customers will be satisfied (EHL, 2021). Additionally, because of the fear of the contraction of the virus, people prefer to stay in hotels which are having good feedback and are trustworthy (Balaji et al., 2021; Lanz, 2020). Also, customers nowadays prefer to stay in the hotels that are responsive and cater to individual customer needs. Kim et al. (2020) have also noted that customers will prefer robotic-staff as compared to human-staff in the post-COVID era to reduce contact with human staff and lessen the risk of getting infected. Interestingly, the authors found that reliability has an insignificant impact contrasting to what Qomariah and Lestari (2019) have found. This might be because of the fact that almost all the hotels nowadays are providing the same information in their websites. Findings show that based on group analysis and comparison between the different hypotheses used in this study, there are different factors which affect the affective loyalty of customers belonging to the two different groups (high-arousal and low-arousal emotion group). However, based on WelchSatterthwait Test and Parametric test, it is observed that there is no significant difference between the two customer groups (high-arousal and low-arousal emotion group) with respect to the hypotheses examined in this study. This shows that there is no significant difference in the drivers of customer loyalty when the comparison is made between the two groups of customers. 


\section{Theoretical and Managerial Implications}

This study has three theoretical implications. First, although the tourism industry has shown its resilience in recovering back from previous crises and outbreaks (e.g., SARS, earthquakes, terrorism, Zika), the impacts of the COVID-19 pandemic has triggered long-term structural changes in the tourism industry (Sigala, 2020). Considering lack of comprehensive studies on the post-COVID protocol implementations, the study offers interesting insights into major trends of hotel industry current protocols in post-COVID era over 500 hotels in 5 different countries within the Asia-Pacific region. The results provide a comprehensive picture of the commonly used practices to fill the current service gaps among hotels. This study thus contributes to the literature on hotel segments in the COVID-19 era. Second, by utilizing text-mining on user-generated data from hotels, the study sheds light on a more systematic and quantitative categorization on topic themes that deepens the understanding of the changes in consumers' behaviors over hotel-staying in post-COVID era for future research. Utilizing user-generated content helps scholars perform both qualitative and quantitative studies in situations when performing traditional qualitative and quantitative studies can be difficult. Third, the study results show that hotels' responsiveness, empathy, credibility, and facilities affect affective loyalty based on structural model analysis using customer reviews. Not only will this new technique help future scholars to understand customer perspectives, but also will allow scholars to utilize the found factors in different scenarios to explore additional values to attract customers.

The findings of the study also generate valuable practical implications for hotel managers in the Asia-pacific region. First, results in this study have shown that the drivers of consumers' behaviour towards hotels differ across countries as the countries are in different stages of combating the COVID-19. For instance, hotel guests in China place a greater emphasis on hotels' locations and food services in a relatively safer post-COVID era. In contrast, Malaysian, Indian, and Indonesian guests expressed great concern over cleanliness, professional room services, safety from COVID-19, room decorations and room space. Hence, as the effect of COVID-19 remains uncertain, hoteliers should pay more attention to its hygiene and functionality of the private space, and food services as guests are spending more time indoors. It is also necessary for hoteliers to be aware of guests' intentions to stay as it can help hotels to develop state-of-art products and services. It is palpable that family 'staycation', 'workcation' and 'celebrations' have become the main reasons for guests to stay at a hotel during the pandemic. Second, as evident from this study, customers are looking for more responsiveness and empathy from hotels. So despite the issues related to shortage of staff, hotel managers need look for ways to improve the response time and consider different customer requests efficiently. Third, as evident from this study, hotel facilities and credibility also affect customer's loyalty. Considering the fact that hotel guests may tend to come in groups, hoteliers should utilize unique facilities, like, intelligent contactless systems to help guests' check-in and check-out as to reduce human contacts and time spend in the lobby for safety issues. Lastly, results of this study showing the important topics used by hotels across different countries will help hotels from other countries look for ways to improve their strategies. Crisis communication on hotel health protocols should be highlighted to its potential guests on social media pages and hotel official websites to lower the guests' perceptions towards health risks when choosing their hotels to stay.

\section{Conclusion and Topics for Future Research}

This study tries to compare the outcomes of analysis conducted on the strategies or operational changes mentioned by 100 hotels from each of the countries, China, Indonesia, India, Malaysia and Thailand. Additionally, this study also tries to explore the drivers of loyalty in the post-COVID era. Results of this study show that while most hotels for communication focus on sanitization, masks and temperature check, the main driver of customer's affective loyalty is hotel's facilities.

This study has a few limitations. First, this study has neglected the influences of different government policies or restrictions imposed on hotels in the five regions selected on customers' perceptions. It is worth noting that government policies control how hotels operate and their strategies, and consequently, influences consumers' perceived risks and social responsibilities. While the hotel chains in different countries tend to implement the same protocols and neglect contextual differences and local government policies, this may compromise the generalizations of our findings. Additionally government help can also help hotels operations in certain countries (Salem et al., 2021). Future scholars can investigate the effect of government policies on the strategies or operational changes adopted by hotels in different countries. Second, this study has considered hotels from Asia-Pacific region only. Future scholars can generalize further by considering hotels from all around the globe. Third, this study has not explored factors like hotel health and hotel flexibility for competitiveness of hotels. Future scholars can explore topics like hotel health and competitiveness, hotel flexibility for competitiveness, hotel industry competitiveness and speed of rebound from pandemics, and cooperation based approaches for hotels to increase competitiveness in the post pandemic era. 


\section{Key Questions Reflecting Applicability in Real Life}

1. What are the strategies or operational changes adopted by hotels in the Asia-Pacific region to attract customers in the post-COVID era?

2. What are the key drivers of customer loyalty while booking hotels in this post-COVID phase?

3. Do the drivers of customer loyalty differ for people belonging to two different emotion groups (high arousal and low arousal)?

4. How to use user-generated content to learn manager or customer perspectives in a qualitative and quantitative manner?

Acknowledgements We would like to thank the anonymous reviewers, the Guest Editors and the editorial team for their efforts and feedback for helping us improve the manuscript. The infrastructural support provided by the FORE School of Management, New Delhi and Taylor's University, Malaysia in completing this paper is gratefully acknowledged.

Author contribution All the authors have contributed equally in this research work.

Funding There is no funding received for conducting this research.

Availability of data and materials Available on request.

Code availability Not applicable.

\section{Declarations}

Conflict of interests There are no conflicts of interest to declare.

\section{References}

Abrudan, I.-N., Pop, C.-M., \& Lazăr, P.-S. (2020). Using a general ordered logit model to explain the influence of hotel facilities, general and sustainability-related, on customer ratings. Sustainability., 12(21), 9302. https://doi.org/10.3390/su12219302

Allard, E. S., Stanley, J. T., Turner, J. R., \& Harrington, A. K. (2020). Age similarities in matching pro- and contra-hedonic emotional strategies to everyday scenarios. Aging, Neuropsychology, and Cognition, 28(2), 161-183. https://doi.org/10.1080/13825585. 2020.17227

Ardani, E. G., \& Harianto, A. (2021). Surviving strategy of hospitality sector in pandemic situation: case hospitality business in Jakarta. E-Journal of Tourism., 8(1), 77-86. https://doi.org/10. 24922/eot.v8i1.71449

Balaji, M. S., Jiang, Y., \& Jha, S. (2021). Nanoinfluencer marketing: how message features affect credibility and behavioral intentions. Journal of Business Research., 136, 293-304. https://doi. org/10.1016/j.jbusres.2021.07.049

Berger, J., Sorensen, A., \& Rasmussen, S. (2010). Positive effects of negative publicity: when negative reviews increase sales.
Marketing Science, 29(5), 815-827. https://doi.org/10.1287/ mksc. 1090.0557

Berman, M., Eaton, L. A., Watson, R. J., Andrepont, J. L., \& Kalichman, S. (2020). Social distancing to mitigate COVID-19 risks is associated with COVID-19 discriminatory attitudes among people living with HIV. Annals of Behavioral Medicine, 54(10), 728-737. https://doi.org/10.1093/abm/kaaa074

Bonfanti, A., Vigalo, V., \& Yfantidou, G. (2021). The impact of the COVID-19 pandemic on customer experience design: the hotel managers' perspective. International Journal of Hospitality Management., 94, 102871. https://doi.org/10.1016/j.ijhm.2021.102871

Boyatzis, R. E. (1998). Transforming qualitative information: thematic analysis and code development. Sage.

Chan, J., Gao, Y. L., \& McGinley, S. (2021). Updates in service standards in hotels: how COVID-19 changed operations. International Journal of Contemporary Hospitality Management, 33(5), 16681687. https://doi.org/10.1108/IJCHM-09-2020-1013

Chatterjee, S. (2020). Drivers of helpfulness of online hotel reviews: a sentiment and emotion mining approach. International Journal of Hospitality Management, 85, 102356. https://doi.org/10.1016/j. ijhm.2019.102356

Clarke, G. (2020). COVID-19: impact could cause equivalent of 195 million job losses, says ILO chief. https://news.un.org/en/story/ 2020/04/1061322. Accessed 18 July 2021.

Creswell, J.W. (2009). Research design. Qualitative, quantitative, and mixed methods approaches. Sage.

Crouch, E. (2020). Breaking Ground on a New Era in Lodging. https:// www.bcg.com/publications/2020/understanding-consumer-behav ior-in-hotel-industry-post-COVID-19. Accessed 18 Aug 2021.

Cucinotta, D., \& Vanelli, M. (2020). WHO declares COVID-19 a pandemic. Acta Bio-Medica Atenei Parmensis, 91(1), 157-160. https://doi.org/10.23750/abm.v91i1.9397

Demir, S.S. (2021). The Effect of COVID-19 measures in hotels on tourists' perceptions of safe tourism service. In (Eds.) M. Demir et al. Handbook of Research on the Impacts and Implications of COVID-19 on the Tourism Industry (2 Volumes). pp. 372-392. https://doi.org/10.4018/978-1-7998-8231-2.ch018

East, R., Hammond, K., \& Lomax, W. (2008). Measuring the impact of positive and negative word of mouth on brand purchase probability. International Journal of Research in Marketing, 25(3), 215-224. https://doi.org/10.1016/j.ijresmar.2008.04.001

EHL (2021). Why empathy skills are crucial for hoteliers. https://hospi talityinsights.ehl.edu/empathy-skills-crucial-hoteliers. Accessed 21 Aug 2021.

Fatima, K. J., \& Razzaque, A. M. (2014). Service quality and satisfaction in the banking sector. International Journal of Quality \& Reliability Management., 31(4), 367-379. https://doi.org/10.1108/ IJQRM-02-2013-0031

Fischer, F., \& Stoffel, F. (2014). NStreamAware: Real-Time visual analytics for data streams (VAST Challenge 2014 MC3). 2014 IEEE Conference on Visual Analytics Science and Technology (VAST). pp. 373-374. https://doi.org/10.1109/vast.2014.7042572

Foo, L.-P., Chin, M.-Y., Tan, K.-L., \& Phuah, K.-T. (2020). The impact of COVID-19 on tourism industry in Malaysia. Current Issues in Tourism. https://doi.org/10.1080/13683500.2020.1777951

Fornell, C., \& Larcker, D. F. (1981). Evaluating structural equation models with unobservable variables and measurement error. Journal of Marketing Research, 18(3), 39-50. https://doi.org/10.2307/ 3151312

Gandhi, F. (2020). Coronavirus impact: Hospitality industry to suffer losses up to ₹620 crore. https://www.thehindubusinessline. com/economy/coronavirus-impact-hospitality-industry-to-sufferlosses-to-the-tune-of-620-crore/article31106611.ece. Accessed 18 Aug 2021.

Gensler, S., Völckner, F., Egger, M., Fischbach, K., \& Schoder, D. (2016). Listen to your customers: Insights into brand image using 
online consumer-generated product reviews. International Journal of Electronic Commerce, 20(1), 112-141. https://doi.org/10.1080/ 10864415.2016.1061792

Hadid, K. I., Omar, S. S., Soon, K. N., \& Amreeghah, A. A. E. (2021). The mediating role of customer satisfaction on the relationship be-tween digital service quality and customer loyalty. Psychology and Education., 58(2), 7033-7044. https://doi.org/10.17762/ pae.v58i2.3246

Hagen, L. (2018). Content analysis of e-petitions with topic modeling: how to train and evaluate LDA models? Information Processing \& Management. https://doi.org/10.1016/j.ipm.2018.05.006

Hair, Jr., Anderson, R.E., Tatham, R.L., \& Black, W.C. (1998). Multivariate Data Analysis with Readings. 5thed Prentice Hall.

Hao, F., Xiao, Q., \& Chon, K. (2020). COVID-19 and China's hotel industry: impacts, a disaster management framework, and postpandemic agenda. International Journal of Hospitality Management, 90, 102636. https://doi.org/10.1016/j.ijhm.2020.102636

Haydon, D., \& Kumar, N. (2020). Industries Most and Least Impacted by COVID-19 from a Probability of Default Perspective-September 2020 Update. https://www.spglobal.com/marketintellige nce/en/news-insights/blog/industries-most-and-least-impactedby-COVID19-from-a-probability-of-default-perspective-septe mber-2020-update. Accessed 18 Aug 2021.

Jian, Y., Yu, I. Y., Yang, M. X., \& Zeng, K. J. (2020). The impacts of fear and uncertainty of COVID-19 on environmental concerns, brand trust, and behavioral intentions toward green hotels. Sustainability., 12(20), 8688. https://doi.org/10.3390/su12208688

Jimenez-Barreto, J., Loureiro, S., Braun, E., Sthapit, E., \& Zenker, S. (2021). Use numbers not words! Communicating hotels' cleaning programs for COVID-19 from the brand perspective. International Journal of Hospitality Management., 94, 102872. https://doi.org/ 10.1016/j.ijhm.2021.102872

Jones, L., Palumbo, D., \& Brown, D. (2021). Coronavirus: How the pandemic has changed the world economy. https://www.bbc.com/ news/business-51706225. Accessed 18 Aug 2021.

Khanna, R. C., Cicinelli, M. V., Gilbert, S. S., Honavar, S. G., \& Murthy, G. (2020). COVID-19 pandemic: lessons learned and future directions. Indian Journal of Ophthalmology, 68(5), 703-710. https://doi.org/10.4103/ijo.IJO_843_20

Kim, S., Kim, J., Badu-Baiden, F., Giroux, M., \& Choi, Y. (2020). Preference for robot service or human service in hotels? Impacts of the COVID-19 pandemic. International Journal of Hospitality Management. https://doi.org/10.1016/j.ijhm.2020.102795

Kiryakova-Dineva, T., \& Bozhkova, R. (2021). Public Health Risk Environment for Bulgarian SMEs (Guest Houses and Family Hotels) in the COVID-19 Pandemic. In: (Eds.) D.R. Toubes and N. Araújo-Vila, Risk, Crisis, and Disaster Management in Small and Medium-Sized Tourism Enterprises. Chapter 4. pp. 77-102. IGI Global.

Krzysztof, P., \& Jadranka, B. V. (2020). Guests' assessment of hotel facilities and services: Zadar case study. European Journal of Tourism, Hospitality and Recreation., 10(3), 241-250.

Kumar, C.R. (2020). COVID-19 Pandemic Impact in India. SSRN. [online] https://ssrn.com/abstract=3637437. Accessed 19 Aug 2021.

Kumar, S., Ghosh, S., \& Mondal, B. (2021). Training-up during COVID-19 in hotel housekeeping operations in selected hotels of Kolkata. Indian Journal of Hospitality Management., 3(1), 89-95.

Lanz, L.H. (2020). The 4 C's of a Hotel's COVID Communications Toolkit: Important Messaging and Touch Points to Consider for Re-Opening. https://www.bu.edu/bhr/2020/06/25/the-4-cs-of-ahotels-COVID-communications-toolkit-important-messagingand-touch-points-to-consider-for-re-opening/. Accessed 21 Aug 2021.

Lee, S. A., Manthiou, A., Jeong, M., Tang, L. R., \& Chiang, L. L. (2014). Does consumers' feeling affect their quality of life? Roles of consumption emotion and its consequences. International Journal of Tourism Research, 17(4), 409-416. https://doi.org/10.1002/ jtr.1988

Lim, N. (2016). Cultural differences in emotion: differences in emotional arousal level between the East and the West. Integrative Medicine Research, 5(2), 105-109.

Lin, L. (2010). The relationship of consumer personality trait, brand personality and brand loyalty: an empirical study of toys and video games buyers. Journal of Product \& Brand Management, 19(1), 4-17. https://doi.org/10.1108/10610421011018347

Liu, C., \& Yang, J. (2021). How hotels adjust technology-based strategy to respond to COVID-19 and gain competitive productivity $(\mathrm{CP})$ : strategic management process and dynamic capabilities. International Journal of Contemporary Hospitality Management. https://doi.org/10.1108/IJCHM-10-2020-1143

Lone, S. A., \& Ahmad, A. (2020). COVID-19 pandemic-an African perspective. Emerging Microbes \& Infections, 9(1), 1300-1308. https://doi.org/10.1080/22221751.2020.177513

Mahon, J., \& Wartick, S. (2003). Dealing with stakeholders: how reputation, credibility and framing influence the game. Corporate Reputation Review., 6, 19-35.

Majumdar, R. (2021). Surviving and growing in the post-COVID world: the case of Indian hotels. Worldwide Hospitality and Tourism Themes. https://doi.org/10.1108/WHATT-05-2021-0064

Manakitsomboon, H. (2021). Value of tourism GDP Thailand 20172020. https://www.statista.com/statistics/1143427/thailand-valueof-tourism-gdp/ (accessed 24 September 2021)

Mishra, V., \& Sharma, M. G. (2021). Framework for promotion of medical tourism: a case of India. International Journal of Global Business and Competitiveness. https://doi.org/10.1007/ s42943-021-00027-7

Nikkei (2021). COVID wave crushes Thailand's already hobbled tourism sector. https://asia.nikkei.com/Business/Business-trends/ COVID-wave-crushes-Thailand-s-already-hobbled-tourism-secto r2. Accessed 18 Aug 2021.

Ojha, R., Mathew, J., \& Venkatesh, U. (2021). Excellence through downstream innovation in times of pandemic: insights from the auto sector. International Journal of Global Business and Competitiveness. https://doi.org/10.1007/s42943-021-00032-w

O'Neill, A. (2021). Share of economic sectors in the GDP in Malaysia 2020. https://www.statista.com/statistics/318732/share-of-econo mic-sectors-in-the-gdp-in-malaysia/. Accessed 24 Sep 2021.

Padmanandam, K., Bheri, S.P.V.D.S., Vegesna, L., \& Sruthi, K. (2021). A Speech Recognized Dynamic Word Cloud Visualization for Text Summarization, 2021 6th International Conference on Inventive Computation Technologies (ICICT), 2021, pp. 609-613. https:// doi.org/10.1109/ICICT50816.2021.9358693

Pandey, J. N., Phasook, J., Sawangsak, S., \& Rodhirun, C. (2021). Crisis management and COVID-19: the case of budget hotels in Muang Chiangmai District. International Journal of Society Systems Science., 13(1), 71-87.

Parra, A. (2013). Cognitive and emotional empathy in relation to five paranormal/anomalous experiences. North American Journal of Psychology. 405-412.

Qomariah, N., \& Lestari, Y. A. (2019). The role of service quality to increase customer satisfaction of Bank Syariah Mandiri Jember. Proceedings of International Seminar Society 5.0 Fostering Spirituality and Humanity., 3(1), 181-199.

Rasa, K., Leonidas, S., \& Gintautas, D. (2020). Kriging predictor for facial emotion recognition using numerical proximities of human emotions. Informatica, 31(2), 249-275. https://doi.org/10.15388/ 20-INFOR419

Ray, A. \& Bala, P.K. (2019). Use of NLP and SEM in Determining Factors for E-Service Adoption. In: Y. Akgul (Eds). Structural equation modeling approaches to E-service adoption. pp. 38-47. https://doi.org/10.4018/978-1-5225-8015-7.ch003 
Ray, A., \& Bala, P. K. (2020). Social media for improved process management in organizations during disasters. Knowledge and Process Management., 27(1), 63-74.

Ray, A., \& Bala, P. K. (2021). User generated content for exploring factors affecting intention to use travel and food delivery services. International Journal of Hospitality Management., 92, 102730. https://doi.org/10.1016/j.ijhm.2020.102730

Ray, A., Bala, P. K., \& Dasgupta, S. A. (2019). Role of authenticity and perceived benefits of online courses on technology based career choice in India: a modified technology adoption model based on career theory. International Journal of Information Management, 47, 140-151. https://doi.org/10.1016/j.ijinfomgt.2019.01

Ray, A., Bala, P. K., \& Jain, R. (2020ab). Utilizing emotion scores for improving classifier performance for predicting consumers' intended ratings from social media posts. Benchmarking: an International Journal. https://doi.org/10.1108/BIJ-01-2020-0004

Ray, A., Bala, P. K., \& Kumar, R. (2020ba). An NLP-SEM approach to examine the gratifications affecting user's choice of different e-learning providers from user tweets. Journal of Decision Systems. https://doi.org/10.1080/12460125.2020.18474

Ray, A., Bala, P. K., \& Rana, N. P. (2021). Exploring the drivers of customers' brand attitudes of online travel agency services: a text-mining based approach. Journal of Business Research, 128, 391-404. https://doi.org/10.1016/j.jbusres.2021.02.028

Ringle, C.M., Wende, S., \& Becker, J.-M. (2015). "SmartPLS 3." Boenningstedt: SmartPLS GmbH. http://www.smartpls.com

Romero, J., \& Lado, N. (2021). Service robots and COVID-19: exploring perceptions of prevention efficacy at hotels in generation $\mathrm{Z}$. International Journal of Contemporary Hospitality Management. https://doi.org/10.1108/IJCHM-10-2020-1214

Salem, I. E., Elbaz, A. M., Elkhwesky, Z., \& Ghazi, K. M. (2021). The COVID-19 pandemic: the mitigating role of government and hotel support of hotel employees in Egypt. Tourism Management, 85, 104305. https://doi.org/10.1016/j.tourman.2021.104305

Shah, A. A., \& Ravana, D. (2014). Evaluating information credibility of digital content using hybrid approach. International Journal of Information Systems and Engineering., 2(1), 92-99.

Sharma, A., Shin, H., Santa-Maria, M. J., \& Nicolau, J. L. (2021). Hotels' COVID-19 innovation and performance. Annals of Tourism Research., 88, 103180. https://doi.org/10.1016/j.annals.2021. 103180

Shrivastava, S., \& Shrivastava, P. (2021). Ensuring safety of guests and staffs in hotels from COVID-19 infection: World Health Organization. Turkish Journal of Family Medicine and Primary Care, 15(1), 12-13. https://doi.org/10.21763/tjfmpc.800040

Sigala, M. (2020). Tourism and COVID-19: Impacts and implications for advancing and resetting industry and research. Journal of Business Research, 117, 312-321. https://doi.org/10.1016/j.jbusres. 2020.06 .015

Straitstimes (2020). Indonesia's tourism industry suffers more than $\$ 9.5 b$ losses due to COVID-19 pandemic. https://www.straitstim es.com/asia/east-asia/indonesias-tourism-industry-suffers-morethan-95b-losses-due-to-COVID-19-pandemic. Accessed 18 Aug 2021.

Taft, M. (1979). Recognition of affixed words and the word frequency effect. Memory \& Cognition, 7, 263-272. https://doi.org/10.3758/ BF03197599
TheStar (2021). Hoteliers: Hospitality industry, among the worst hit by pandemic, has lost RM11.3bil to date. https://www.thestar.com. my/news/nation/2021/06/25/hoteliers-hospitality-industry-amongthe-worst-hit-by-pandemic-has-lost-rm113bil-to-date. Accessed 18 Aug 2021.

Tyagi, A. (2020). For hospitality and tourism sector, 2021 is all about survival, recovery. https://www.livemint.com/industry/humanresource/for-hospitality-and-tourism-sector-2021-is-all-aboutsurvival-recovery-11608544204065.html. Accessed 18 Aug 2021.

Wang, S., \& Wang, J. (2021). Service quality evaluation method of city shared bicycles based on SERVQUAL model. EDP Sciences. https://doi.org/10.1051/e3sconf/202123603022

Yacoub, L., \& ElHajjar, S. (2021). How do hotels in developing countries manage the impact of COVID-19? The case of Lebanese hotels. International Journal of Contemporary Hospitality Management, 33(3), 929-948. https://doi.org/10.1108/ IJCHM-08-2020-0814

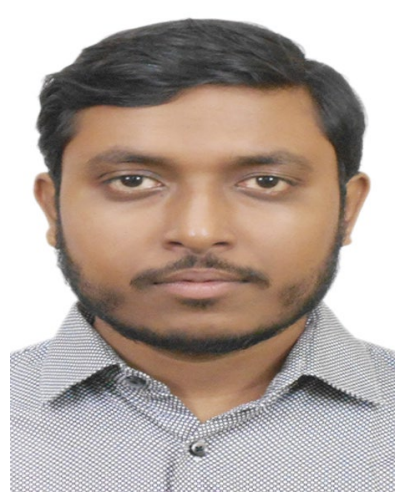

Arghya Ray is an Assistant Professor at FORE School of Management, Delhi. He had earlier worked as an Assistant Professor in ADAMAS University, and as a Visiting Faculty at Birla Global University. He has done his $\mathrm{PhD}$ from IIM Ranchi in the area of Information Systems and Business Analytics and received his B.Tech. in Computer Science and Engineering from SRM University. He has also worked at Tata Consultancy Services as a System Engineer for two years. His areas of interest include Text Mining \& NLP, Recommender Systems, Data mining applications and algorithms, Business Analytics, Marketing Analytics and Computer Networks.

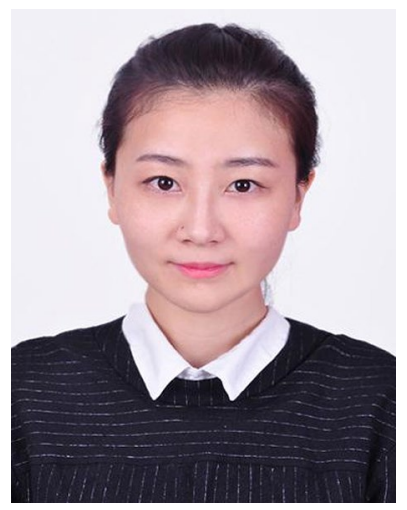

Lan $\mathrm{Ma}$ is a PhD scholar in Faculty of Business and Law, Taylor's University, Malaysia. She has been granted a full scholarship and involved in several research projects. She holds a master's degree from University of Birmingham and a Bachelor of English in University of Malaya. Her research interests include the applications of machine learning in consumer behaviour and online education. 